\title{
PENGATURAN KERAPATAN TEGAKAN BAMBANG BERDASARKAN HUBUNGAN ANTARA DIAMETER BATANG DAN TAJUK
}

\author{
Bambang (Michelia champaca) Stand Density Arrangement Base on Diametre Breast \\ Heigh and Crown Diametre Relationship
}

Agus Sumadi dan Hengki Siahaan

Balai Penelitian Kehutanan Palembang

Jl. Kol. H. Burlian Km 6,5 Kotak Pos 179, Puntikayu, Palembang

Telp./Fax. (0711) 414864

Naskah masuk : 21 Februari 2011; Naskah diterima : 25 Oktober 2011

\begin{abstract}
Stand density arrangement plays an important role on development of plantation forest to obtain optimal result. This research presents a way of bambang stand density arrangement based on crown development. Optimal crown area (ca) is determined by regression equation between diameter of breast heigh (dbh) and crown diameter $(\mathrm{cd})$. While stand density is determined by dividing plantation area with optimal crown area (ca). Data collection was carry out by measuring 380 tree sample on farm forestry in Lahat Regency, Empat Lawang Regency, and Pagar Alam City. Regression equation both variable was formulated based on 280 tree samples and validated of 100 samples remain. Result showed that correlation equation between diametre brest heigh and crown diametre with the highest accuration is quadratic equation $C d=$ $3.15+0.0391 \mathrm{Dbh}+0.00251 \mathrm{Dbh}^{2}\left(R^{2} 68.52 \%\right.$, bias $0.2 \%$ dan RMSE $\left.73.76 \%\right)$.
\end{abstract}

Keywords: Bambang, diametre breast height, crown diametre, stand density

\begin{abstract}
ABSTRAK
Pengaturan kerapatan tegakan merupakan hal penting dalam pembangunan hutan tanaman untuk memperoleh hasil yang optimal. Penelitian ini menyajikan suatu cara pengaturan kerapatan tegakan bambang (Michelia champaca) berdasarkan perkembangan tajuk. Luas tajuk optimal (ca) ditentukan berdasarkan hubungan regresi antara diameter batang setinggi dada (dbh) dengan diameter tajuk (cd). Kerapatan tegakan ditentukan oleh pembagian luas areal penanaman dengan luas tajuk optimal. Pengumpulan data dilakukan pada 380 pohon sampel yang terdapat pada hutan rakyat di Kabupaten Lahat, Kabupaten Empat Lawang, dan Kota Pagar Alam. Persamaan regresi kedua variabel dibangun menggunakan 280 data dan divalidasi dengan 100 data yang tersisa. Hasil penelitian menunjukkan bahwa persamaan hubungan antara diameter tajuk dan diameter batang bambang yang memiliki ketelitian tertinggi adalah persamaan kuadratik dengan rumus $\mathrm{Cd}=3,15+0,0391 \mathrm{Dbh}+0,00251 \mathrm{Dbh}^{2}\left(\mathrm{R}^{2} 68,52 \%\right.$, bias $0,2 \%$ dan RMSE 73,76\%).
\end{abstract}

Kata kunci: Bambang, diameter batang, diameter tajuk, kerapatan tegakan

\section{PENDAhUluAN}

Bambang termasuk dalam famili magnoliaceae dengan nama ilmiah Michelia champaca. Pohon bambang merupakan jenis kayu pertukangan dengan pertumbuhan cepat yang menjadi unggulan Provinsi Sumatera
Selatan khususnya Kabupaten Empat Lawang, Kabupaten Lahat dan Kota Pagar Alam. Jenis ini sudah dikembangkan secara luas oleh masyarakat baik dengan pola monokultur maupun pola campuran.

Budidaya bambang oleh masyarakat masih dilakukan secara sederhana. Salah satu 
cirinya adalah belum adanya pengaturan kerapatan melalui pengaturan jarak tanam dan penjarangan. Pengaturan kerapatan dilakukan untuk memanfaatkan lahan secara optimal berdasarkan kebutuhan tanaman akan ruang dan sumberdaya yang meningkat sejalan dengan pertumbuhannya tahun demi tahun. Pada saat penanaman, tanaman dapat ditanam dengan jarak tanam yang rapat agar batang tanaman tumbuh lurus dan meninggi. Sejalan dengan waktu, kerapatan harus dikurangi untuk menyediakan ruang tumbuh bagi perkembangan tajuk dan daerah perakaran serta untuk memacu pertumbuhan lateral (diameter).

Perkembangan tajuk dapat digunakan sebagai dasar pengaturan kerapatan tegakan karena perkembangan tajuk menggambarkan ruang yang diperlukan oleh pohon untuk dapat tumbuh secara optimal. Ruang yang diperlukan oleh tajuk dapat menjadi dasar dalam menggambarkan pertumbuhan pohon serta memberikan gambaran kompetisi antara pohon. Menurut Hann (1997), persamaan untuk memprediksi dimensi tajuk di lokasi terbuka dengan mempertimbangkan potensi biologi perkembangan tajuk secara maksimum dikenal sebagai maximum crown width (MCW), sedangkan persamaan untuk pohon dengan tajuk kecil karena adanya persaingan, disebut largest crown width (LCW). LCW sering digunakan dalam prediksi lebar tajuk pohon dalam tegakan hutan.

Pembuatan persamaan allometrik hubungan antara diameter batang dan diameter tajuk dapat menjadi dasar dalam menentukan jarak tanam optimal dan mengatur kerapatan tegakan saat penjarangan (Zuhaidi, 2009) serta menurut Vanclay (1994) pemodelan lebar tajuk dapat dijadikan indikator persaingan pohon. Tulisan ini bertujuan untuk menyajikan suatu cara pengaturan kerapatan tegakan bambang (Michelia champaca) berdasarkan perkembangan tajuk.

\section{METODOLOGI}

\section{A. Lokasi Penelitian}

Kegiatan penelitian dilakukan pada tegakan bambang ( $M$. champaca) yang dikembangkan oleh masyarakat pada hutan rakyat yang ada di Kabupaten Empat Lawang, Kabupaten Lahat dan Kota Pagar Alam, Provinsi Sumatera Selatan. Lokasi penelitian ini berada pada ketinggian $150-1.100 \mathrm{~m}$ dpl.

\section{B. Bahan Penelitian}

Penelitian dilakukan pada pohon model (kisaran) diameter antara 5,5 - 52,0 cm yang memiliki batang dan tajuk normal untuk mengetahui besarnya ruang tumbuh pohon pada pengukuran diameter tajuk dilakukan 2 kali, yaitu pada arah Utara-Selatan dan Barat-Timur.

\section{Analisis Data}

\section{Analisis Regresi}

Analisis data dilakukan dengan melakukan regresi antara peubah bebas diameter setinggi dada (Dbh) dengan peubah tak bebas diameter tajuk/crown diameter $(\mathrm{Cd})$. Analisis regresi dilakukan dengan menggunakan program SPSS. Persamaan regresi yang digunakan untuk menggambarkan hubungan kedua variabel adalah sebagai berikut:

$$
\begin{aligned}
& \mathrm{Cd}=\alpha_{0}+\alpha_{1} \mathrm{dbh} \\
& \mathrm{Cd}=\alpha_{0}+\alpha_{1} \mathrm{dbh}^{2} \\
& \mathrm{Cd}=\alpha_{0}+\alpha_{1} \ln \mathrm{dbh} \\
& \mathrm{Cd}=\alpha_{0}+\alpha_{1} \mathrm{dbh}+\alpha_{2} \mathrm{dbh}^{2}
\end{aligned}
$$

Keterangan:

$\mathrm{Cd} \quad$ : Diameter tajuk (m)

Dbh : Diameter batang setinggi dada $(\mathrm{cm})$

$\mathrm{A}_{0} \quad$ : Konstanta

$\alpha_{1}, \alpha_{2}$ : Koefisien regresi

\section{Pemilihan Model Terbaik}

Pemilihan model terbaik menurut Gonzalez et al. (2007) ada tiga uji statistik dalam evaluasi model terbaik diantaranya koefisian determinasi yang disesuaikan $\left(\mathrm{R}_{\text {adj }}^{2}\right)$, bias, dan akar rata-rata kuadrat simpangan (Root mean square error) disingkat RMSE. Koefisien determinasi menggambarkan proporsi variasi total di sekitar nilai tengah yang dapat dijelaskan oleh regresi. Penggunaan $\mathrm{R}_{\text {adj }}{ }^{2}$ dilakukan karena model yang diuji mempunyai jumlah parameter yang berbeda, sehingga perlu penyesuaian koefisien determinasi yang digunakan. Bias menggambarkan penyimpangan antara pendugaan model dan data hasil pengamatan dan root mean square error (RMSE) menggambarkan ketepatan dari pendugaan. Koefisien determinasi $\left(\mathrm{R}_{\text {adj }}^{2}\right)$ diperoleh dari data penyusun model sedangkan bias dan RMSE diperoleh dari data independen untuk validasi model. Persamaan dari tiga uji statistik tersebut adalah: 
$R_{a d j}^{2}=1-\frac{\sum_{i=1}^{n}\left(y_{i}-\hat{y}_{i}\right) /(n-p)}{\sum_{i=1}^{n}\left(y_{i}-\hat{y}_{i}\right) /(n-p)}$

Bias $-\frac{\sum_{i=1}^{n}\left(y_{i}-\hat{y}_{i}\right)}{n}$

$R M S E-\sqrt{\frac{\sum_{i=1}^{n}\left(y_{i}-\hat{y}_{i}\right)^{2}}{n-p}}$

Keterangan:

yi : nilai pengukuran ke-i

$\hat{y}$ : nilai dugaan dari pengukuran ke-i

$\mathrm{y}:$ rata-rata nilai pengukuran

$\mathrm{n}$ : jumlah unit contoh

$\mathrm{p}:$ jumlah parameter

\section{HASIL DAN PEMBAHASAN}

\section{A. Sebaran Data}

Pengukuran dimensi pohon yang menjadi objek penelitian dilakukan terhadap 380 pohon sampel yang terdapat pada 16 plot PUP yang tersebar di tiga kabupaten/kota. Pohon sampel yang terdapat di Kabupaten Empat Lawang mewakili tegakan yang berada pada ketinggian 100 - 200 m dpl, Kabupaten Lahat mewakili ketinggian tempat $350-450 \mathrm{~m}$ dpl serta Kota Pagar Alam mewakili ketinggian $700-1.200 \mathrm{~m}$ dpl. Penyusunan model diperoleh dari penggunaan 280 data digunakan sebagai data penyusun model dan sisanya 100 data digunakan untuk validasi model. Nilai maksimum dan minimum, rata-rata dan simpangan baku masing-masing data disajikan pada Tabel 1 .

Tabel(Table) 1. Ringkasan data dbh dan diameter tajuk untuk (Data summary of dbh and crown diametre)

\begin{tabular}{|l|c|c|c|c|}
\hline \multicolumn{1}{|c|}{ Variabel } & Jumlah & Minimum & Maximum & Mean \\
\hline Data Model & & & & \\
Dbh (cm) & 280 & 5,50 & 52,00 & $18,64 \pm 0,50$ \\
Diameter Tajuk (m) & 280 & 2,30 & 12,75 & $4,91 \pm 0,09$ \\
Data Validasi & & & & \\
Dbh (cm) & 100 & 5,90 & 51,00 & $19,48 \pm 0,89$ \\
Diameter tajuk (m) & 100 & 2,40 & 11,15 & $5,05 \pm 0,16$ \\
\hline
\end{tabular}

Data penyusun persamaan regresi sebanyak 280 data dengan diameter batang ratarata $18,64 \pm 0,50 \mathrm{~cm}$ dan rata-rata diameter tajuk $4,91 \pm 0,09 \mathrm{~m}$, sedangkan data validasi model rata-rata diameter batang $19,48 \pm 0,89 \mathrm{~cm}$ serta rata-rata diameter tajuk 5,05 $\pm 0,16 \mathrm{~m}$. Sebaran data penyusun persamaan regresi dan data validasi seperti pada digambarkan pada Gambar 1.

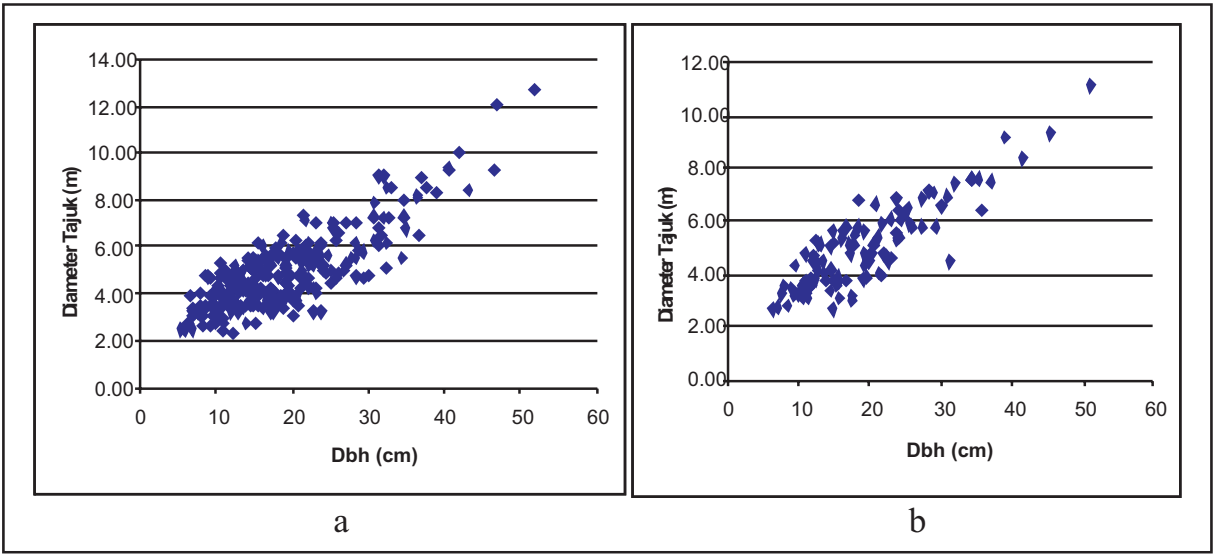

Gambar(Figure) 1. a. Sebaran data penyusun model, b. data validasi model (a. Fitting data model distribution, $b$. validating of data model distribution) 


\section{B. Pemilihan Model}

Persamaan regresi dibangun berdasarkan peubah bebas diameter setinggi dada dan peubah tak bebas diameter tajuk. Nilai $\mathrm{R}_{\text {adi }}^{2}$, bias dan
RMSE pada tiap persamaan penyusun persamaan disajikan pada Tabel 2 serta pemberian skoring dan peringkat gabungan masing-masing persamaan disajikan pada Tabel 3 .

Tabel (Table) 2. Nilai $\mathrm{R}_{\text {adj }}^{2}$, bias dan RMSE pada tiap persamaan yang diuji $\left(R_{\text {adj }}^{2}\right.$, bias and $R M S E$ value for each equation tested)

\begin{tabular}{|c|l|c|c|c|}
\hline No. & \multicolumn{1}{|c|}{ Model } & $\mathrm{R}_{\text {adj }}^{2}$ & Bias & RMSE \\
\hline 1 & $\mathrm{Cd}=2.02+0.156 \mathrm{Dbh}$ & $67,37 \%$ & 0,010 & 0,7578 \\
2 & $\mathrm{Cd}=3.54+0.00330 \mathrm{Dbh}^{2}$ & $69,60 \%$ & 0,009 & 0,7563 \\
3 & $\mathrm{Cd}=-2.92+2.77 \mathrm{LnDbh}$ & $57,94 \%$ & 0,012 & 0,9139 \\
4 & $\mathrm{Cd}=3.15+0.0391 \mathrm{Dbh}+0.0025 \mathrm{Dbh}^{2}$ & $69,76 \%$ & 0,002 & 0,7376 \\
\hline
\end{tabular}

Tabel(Table) 3. Skoring dan peringkat gabungan tiap persamaan (Skoring and ranking for each equation tested)

\begin{tabular}{|c|l|c|c|c|c|c|}
\hline \multirow{2}{*}{ No, } & Model & \multicolumn{3}{|c|}{ Skoring/ scoring } & $\begin{array}{c}\text { Jumlah } \\
\text { skor/ Sum } \\
\text { of score }\end{array}$ & $\begin{array}{c}\text { Peringkat } \\
\text { gabungan/ } \\
\text { ranking }\end{array}$ \\
\cline { 3 - 7 } & & $\mathrm{R}^{2}$ adj & Bias & RMSE & 3 \\
2 & $\mathrm{Cd}=2.02+0.156 \mathrm{Dbh}$ & 3 & 3 & 3 & 9 & 3 \\
3 & $\mathrm{Cd}=3.54+0.00330 \mathrm{Dbh}^{2}$ & 2 & 2 & 2 & 6 & 2 \\
4 & $\mathrm{Cd}=-2.92+2.77 \mathrm{LnDbh}$ & 4 & 4 & 4 & 12 & 4 \\
& $\mathrm{Cd}=3.15+0.0391 \mathrm{Dbh}+$ & 1 & 1 & 1 & 3 & 1 \\
\hline
\end{tabular}

Keempat persamaan yang digunakan untuk menggambarkan hubungan antara diameter batang dan tajuk pohon bambang mempunyai kemampuan yang berbeda dalam menggambarkan hubungan kedua variabel yang ditunjukkan oleh perbedaan nilai koefisien determinasi masing-masing persamaan. Persamaan satu merupakan persamaan linier menghasilkan koefisien determinasi $\left(\mathrm{R}_{\text {adj }}^{2}\right)$ sebesar $67,37 \%$. Nilai koefisien determinasi ini memberikan gambaran keragaman diameter tajuk yang dapat diterangkan oleh keragaman diameter batang sebesar $67,37 \%$ sedangkan $32,63 \%$ keragaman diameter tajuk diterangkan oleh variabel lain. Pada persamaan dua dengan mengkuadratkan peubah tak bebas diameter dapat meningkatkan koefisien determinasi sebesar 2,23\% sedangkan pada persamaan 3 yang merupakan persamaan logaritmik cenderung menurunkan nilai koefisien determinasi sebesar 2,39\%. Persamaan ke empat merupakan persamaan kuadratik dengan varibel Dbh dan $\mathrm{Dbh}^{2}$. Persamaan ini mempunyai nilai koefisien determinasi tertinggi atau meningkat sekitar 2,01\% dibandingkan persamaan linier (persamaan satu), sehingga pada Tabel 3 persamaan ini mendapatkan skoring satu.

Bias memberikan gambaran penyimpangan antara nilai yang diberikan oleh model dengan data baru (independent data) hasil pengukuran yang tidak digunakan untuk menyusun model. Menurut Huang et al. (2003) model fitting berdasarkan data yang digunakan untuk penyusunan model belum tentu mencerminkan kualitas hasil prediksi model, sehingga validasi model harus dilakukan dengan menggunakan independent data yang tidak digunakan untuk menyusun model. Persamaan linier menghasilkan bias sebesar 1\%, sedangkan persamaan dua dapat menurukan bias sebesar $0,1 \%$ sedangkan pada persamaan logaritmik 
cenderung meningkatkan bias sebesar $0,2 \%$. Persamaan kuadratik merupakan persamaan dengan bias terkecil sebesar $0,2 \%$ atau menurunkan bias sebesar $0,8 \%$ dibandingkan pada persamaan linier sehingga persamaan ini mendapatkan skoring satu seperti pada Tabel 3 di atas.

Nilai RMSE menggambarkan ketepatan dari pendugaan. Berdasarkan analisis menggunakan data independen, persamaan kuadratik merupakan persamaan yang memiliki nilai terendah. Penggunaan persamaan kuadratik dalam memberikan gambaran hubungan antara diameter tajuk dengan diameter batang memberikan ketepatan yang paling akurat. Persamaan kuadratik meningkatkan ketepatan dalam pendugaan sebesar $2,02 \%$ dibandingkan persamaan linier. Pada Tabel 3 persamaan kuadratik mendapatkan nilai skoring satu sedangkan persamaan logaritma memiliki skoring empat.
Persamaan regresi hubungan antara diameter tajuk dan diameter batang berdasarkan peringkat gabungan persamaan kuadratik $\mathrm{Cd}=$ 3,15+ 0,0391 Dbh + 0,00251 $\mathrm{Dbh}^{2}$ merupakan persamaan yang memiliki ketelitian tertinggi. Penggunaan persamaan kuadratik ini sesuai dengan hasil penelitian Bechtold (2003) bahwa hubungan antara diameter batang dan diameter tajuk berpola kuadratik untuk beberapa jenis pohon di Amerika Serikat Bagian Timur.

Pola sebaran data hubungan diameter batang-tajuk dan kurva yang dibentuk oleh tiap persamaan yang diperoleh digambarkan pada Gambar 2. Berdasarkan gambar tersebut persamaan kuadratik merupakan persamaan yang memiliki pola yang lebih sesuai dengan sebaran data hubungan antara kedua variabel.

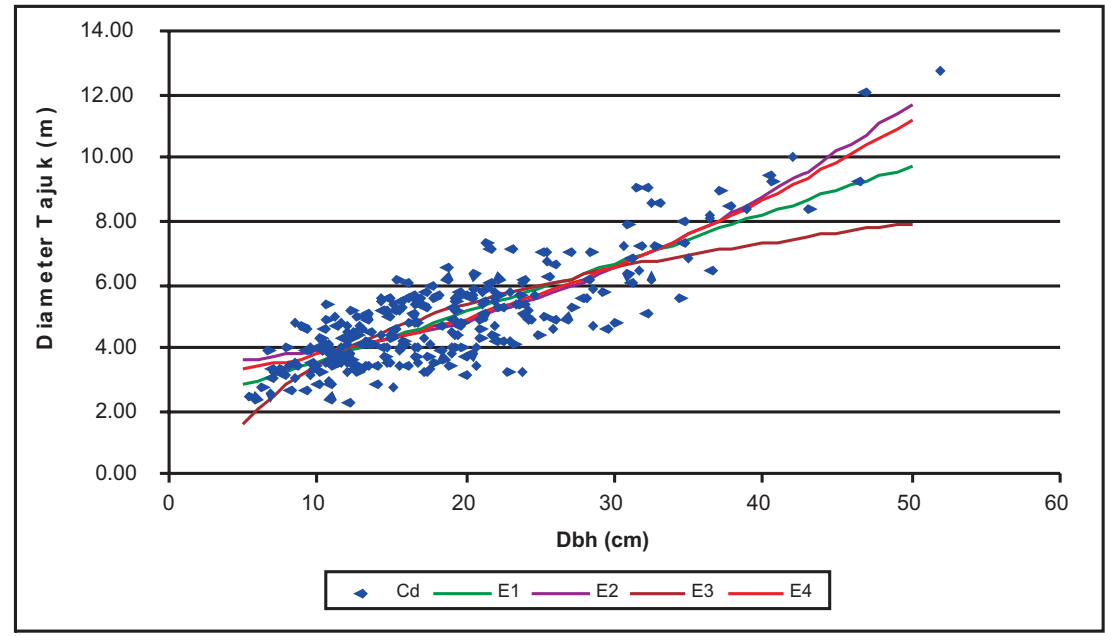

Gambar(Figure) 2. Hubungan antara dbh dengan diameter tajuk pada keempat persamaan yang diuji (Dbh and crown diameter relationship for the forth equations tested)

\section{Pengaturan Kerapatan Tegakan}

Persamaan yang menggambarkan hubungan dbh dan diameter tajuk pohon bambang dapat digunakan untuk menentukan jarak tanam dan kerapatan optimal pada pembangunan hutan tanaman bambang. Kerapatan tegakan optimal diperoleh dengan membagi luas areal penanaman dengan ruang/areal yang diperlukan oleh tajuk untuk tumbuh normal. Berdasarkan persamaan terbaik yang menggambarkan hubungan dbh dan diameter tajuk yang diperoleh yaitu $\mathrm{Cd}=3,15+$ 0,0391 $\mathrm{Dbh}+0,00251 \mathrm{Dbh}^{2}$, dapat diperoleh besarnya diameter tajuk optimal pada nilai dbh tertentu. Nilai diameter tajuk optimal digunakan untuk menghitung luas penutupan tajuk optimal yang selanjutnya dapat digunakan untuk menghitung jumlah individu tegakan dalam satu satuan luas. Pada Tabel 4 disajikan jumlah individu pohon (kerapatan tegakan) dalam satu hektar lahan pada diameter tegakan tertentu. 
Tabel(Table) 4. Nilai diameter tajuk, luas tajuk dan jumlah pohon/ha berdasarkan persamaan terpilih (Crown diametre value, crown area, and number of tree per hectare base on selected equation)

\begin{tabular}{|c|c|c|c|}
\hline Dbh $(\mathrm{cm})$ & $\mathrm{Cd}(\mathrm{m})$ & $\mathrm{Ca}\left(\mathrm{m}^{2}\right)$ & $\begin{array}{c}\text { Kerapatan tegakan } \\
(\mathrm{N} / \mathrm{ha})\end{array}$ \\
\hline 4 & 3,35 & 8,80 & 1.136 \\
6 & 3,47 & 9,49 & 1.054 \\
8 & 3,62 & 10,32 & 969 \\
10 & 3,79 & 11,30 & 885 \\
12 & 3,98 & 12,45 & 803 \\
14 & 4,15 & 13,79 & 725 \\
16 & 4,42 & 15,34 & 652 \\
18 & 4,67 & 17,11 & 584 \\
20 & 4,94 & 19,14 & 522 \\
22 & 5,23 & 21,45 & 466 \\
24 & 5,53 & 24,06 & 416 \\
26 & 5,86 & 27,01 & 370 \\
28 & 6,21 & 30,33 & 330 \\
30 & 6,58 & 34,04 & 294 \\
32 & 6,97 & 38,19 & 262 \\
34 & 7,38 & 42,80 & 234 \\
36 & 7,81 & 47,93 & 209 \\
38 & 8,26 & 53,61 & 187 \\
40 & 8,73 & 59,88 & 167 \\
\hline
\end{tabular}

Tabel 4 yang menyajikan hubungan antara dbh, diameter tajuk, dan kerapatan tegakan dapat digunakan sebagai panduan dalam kegiatan penjarangan. Kebutuhan individu pohon terhadap ruang disesuiakan dengan perkembangan tajuknya yang bertambah besar sejalan dengan pertumbuhan diameter batangnya. Hal ini juga sejalan dengan pendapat Krajicek dalam Daniel et al. (1987) bahwa luas penutupan tajuk menggambarkan besarnya ruang tumbuh optimal yang dapat digunakan oleh pohon dalam suatu tegakan.

Tateno dan Kawaguchi (2002) menyatakan bahwa pada komunitas hutan, intensitas cahaya yang tersedia untuk individu pohon pada posisi vertikal berbeda secara besar. Hal tersebut sejalan dengan pernyataan Yoda (1974) yang diacu oleh Chazdon et al. (1996) bahwa gradien intensitas cahaya di hutan El Pasoh, Malaysia memperlihatkan penurunan PAR (Photosynthethically Active Radiation) secara eksponensial dari tajuk lapisan atas (pada ketinggian pohon 30 m) sampai ke lantai hutan. Kondisi ini yang menjadi landasan ilmiah bahwa ruang tumbuh sangat berperan penting dalam besaran cahaya yang diterima oleh tegakan untuk proses fisiologinya.
Apabila riap diameter tegakan telah diketahui, maka besarnya dbh pada umur tertentu dapat diketahui sehingga waktu pelaksanaan kegiatan penjarangan dapat ditentukan secara tepat. Pelaksanaan penjarangan yang tepat waktu diharapkan dapat meningkatkan produktivitas tegakan hutan tanaman bambang.

\section{KESIMPULAN}

Persamaan hubungan antara diameter tajuk dan diameter batang yang memiliki ketelitian tertinggi adalah persamaan kuadratik dengan rumus $\mathrm{Cd}=3,15+0,0391 \mathrm{Dbh}+0,00251$ Dbh $^{2}$. Persamaan ini memiliki nilai $\mathrm{R}^{2} 68,52 \%$, bias $0,2 \%$ dan RMSE $73,76 \%$. Persamaan ini dapat menjadi dasar dalam perhitungan kerapatan optimal tegakan bambang.

\section{DAFTAR PUSTAKA}

Bechtold, W.A., 2003. Crown-Diameter Prediction Models for 87 Species of StandGrown Trees in the Eastern United States. Southern Journal of Applied Forestry, Volume 27, Number 4, pp. 269-278(10). 
Chazdon, R.L. And N. Fetcher. 1984. Light Environments of Tropical Forests. In. Physiological Ecology of Plants of the Wet Tropics (Medina, E., H.A. Mooney \& C. Vazquez-Yanes, editor). Dr W. Junk Publishers, The Hague, Netherlands : 2750.

Daniel, T.W., J.A. Helms., dan F.S. Baker, 1987. Prinsip-Prinsip Silvikultur. (Oemi HS, editor). Gadjah Mada University Press.

Gonzales, M.S., I Canellas and G. Montero. 2007. Generalized Height Diameter and Crown Diameter Prediction Models for Cork Oak in Forests in Spain. Sistemas y Recursor Forestales 2007 16 (1). 76-88.

Hann. D.W., 1997. Equations for Predicting the Largest Crown Width of Stand-Grown
Trees in Western Oregon. ForRes Lab, Oregon State Univ, Corvallis. Res Contrib $17.14 \mathrm{pp}$.

Tateno, R. and H. Kawaguchi. 2002. Differences in Nitrogen use Efficiency between Leaves from Canopy and Subcanopy Trees. Ecological Research 17: 695 - 704.

Zuhaidi, Y.A. 2009. Local Growth Model In Modelling The Crown Diameter of Plantation-Grown Dryobalanops Aromatica. Journal of Tropical Forest Science 21(1): 6671.

Vancly. JK. 1994. Modelling Forest Growth and Yield. Application to Mixed Tropical Forest. Centre for Agriculture and Biosciences International, Wallingford. 